Original Research Paper

\title{
Cost-Effective Energy Refurbishment of Health Care Facilities in Heating Dominated Climates of Italian Backcountry. The Case Study of the Hospital Veneziale of Isernia
}

\author{
${ }^{1}$ Rosa Francesca De Masi, ${ }^{2}$ Fabrizio Ascione, ${ }^{3}$ Gennaro Sosto and ${ }^{4}$ Giuseppe Peter Vanoli \\ ${ }^{1}$ Department of Engineering, Università degli Studi del Sannio, 82100 Benevento, Italy \\ ${ }^{2}$ Department of Industrial Engineering, Università degli Studi di Napoli Federico II, 80125 Napoli, Italy \\ ${ }^{3}$ Director of Molise Public Health, A.S.R.E.M., Azienda Sanitaria Regionale del Molise, 86100 Campobasso, Italy \\ ${ }^{4}$ Department of Medicine and Health Sciences - Vincenzo Tiberio, Università del Molise, 86100 Campobasso, Italy
}

Article history

Received: 07-07-2017

Revised: $10-07-2017$

Accepted: 8-09-2017

Corresponding Author:

Fabrizio Ascione

Department of Industrial

Engineering, Università degli

Studi di Napoli Federico II,

80125 Napoli, Italy

Email: fabrizio.ascione@unina.it

\begin{abstract}
Maximizing energy efficiency within hospitals and healthcare facilities is a major challenge for sustainable development and energy saving objectives. In this study, the case study of the public hospital of Isernia (Italian backcountry city) is proposed, being typical of the hospital building stock developed in reinforced concrete all around Italy in the last 40 years. Starting from deep on-site investigations, based on direct surveys and documents, a transient energy model has been developed and calibrated, in order to reproduce the present scenario. This, in a next phase, has been modified for proposing a multi-target optimization of energy performances, by taking into consideration all main uses (heating, cooling, ventilation, lighting, domestic hot water), by refurbishing the building envelope, active energy systems and providing energy conversion from renewables. The whole energy retrofit, formulated on the basis of a multi-stage optimization problem, resulted technically efficient and economically feasible. Moreover, the peculiarities of the case study and of the method make that investigation repeatable with reference to both studying approach and outcomes.
\end{abstract}

Keywords: Energy Audit, Energy Retrofit, Dynamic Simulation Modeling, Cost-Optimal Analysis, Hospital Buildings

\section{Introduction}

According to recent trends, challenges and guidelines of energy efficient and sustainable buildings, European community (EUP, 2010) requires a demonstrative and exemplary role of the public hand, so that all owned or managed buildings are required to perform, energetically, even better compared the ones of the private sector. In this regard, a particular function of public buildings is particularly energy-intensive: Hospitals and, more in general, all health care facilities. This is due to the high functional complexity of such edifices, that usually host several very different functions, going from ordinary uses of the tertiary sector (i.e., ambulatories, offices) to rooms that have to be controlled all day long (patient wards) or with very restrictive conditions of indoor humidity and temperatures, such as all surgery blocks and white rooms. In addition, it should be noted that other requirements, such as the microclimatic stability, the quality of indoor air, the assurance of avoiding possible contamination among different zones, make this challenge even more complicated.

The specific requirements for the thermal comfort of patients, visitor, doctors and staff have been studied by Sattayakorn et al. (2017) with reference to large-scale general hospitals in the urban context of Bangkok. Guidelines for Design and construction of hospital and health care facilities have been proposed by several international (AIA, 2006; ASHRAE, 2011) and national institutions. Referring to Italian legislation, guidelines and requirements are reported by a Ministerial Act 
(IMPW, 1974), a Presidential Decree (PIR, 1997) and by the guidelines of Italian National Institute for Prevention and Work Safety (ISPESL, 2002).

About the approach with which refurbishment interventions can be examined, Capozzoli et al. (2016) have proposed a novel methodology to perform an energy consumption benchmarking analysis based on LMEM and Monte Carlo simulation. Moreover, Ascione et al. (2016) have suggested a multi-stage and multi-objective (Pareto) methodology to identify robust cost-optimal energy retrofit solutions.

The application of energy saving measures can be either at the shell of the building or at the electromechanical installations or by installing passive and active renewable energy sources (Ascione, 2017). The report "guidelines for energy efficiency in hospitals" (EPTA Ltd., 2007) subdivides energy efficiency measures in categories, based on the sector of energy consumption of the building to which they are referred to and on the expenditures that is required for their implementation. The key barriers to the implementation of energy-efficient technologies have been studied by Wang et al. (2016). Several energy efficiency measures, for both building envelope and HVAC systems, have been analyzed by Ascione et al. (2016) for the Hospitals in Mediterranean climate. Moreover, Biglia et al. (2017) have presented an investigation for evaluating the suitability of CHP for an Italian Hospital, also in this case in Mediterranean climate (i.e., Sardinia). Teke and Timur (2014) have shown that heat exchangers should be used for the heat recovery in the heating systems as well as cogeneration or trigeneration systems can be considered to increase the overall efficiency. In the same vein, Buonomano et al. (2014) have concluded that timeprogrammable regulation of the classrooms is probably the most profitable action, as well as a centralized heating regulation is more profitable compared to the room one. The simulation results of Radwan et al. (2016) for Egyptian hospitals have shown that application of a demand control ventilation system allows electricity saving of around $41 \%$. Carbonari et al. (2015) have demonstrated that in acute hospitals, the energy consumptions can be reduced by up to $77 \%$ with high investments, while savings are no lower than 35$40 \%$ with low cost investment in clinics.

Briefly, hospital and healthcare facilities have great potentialities in terms of energy saving. However, previous scientific works don't deal in detail the costeffective aspect of the hospital refurbishment as well as the reduction of polluting emissions due to exercise consumptions. Also the methodological approach for studying energy performance and indoor comfort conditions is not always investigated as deeply as required. Herein, the main novelty of the proposed. Indeed, it discusses the applicability of a multi-stage and multi-objective optimization methodology in order to select energy efficiency measures for hospital buildings in middle-cold climate. The aim is to evaluate if a significant energy refurbishment is possible, by taking into account also the environmental and economic feasibility. This could mean that the building requires low expenditures for operating, with a consequent increase of its exemplary role, by allowing also a more comfortable environment for people that must stay and work inside it all day long.

\section{Aim of the Investigation and Methodology}

The proposed approach consists of a multi-step optimization process with two sequential phases. First of all, a multi-objective optimization is applied in order to provide the best trade-off among transparent envelope solutions, insulation of the building and radiative characteristics of roof for hospital buildings with high heating consumptions. The multi-objective optimization problem is set by developing the energy model for the hospital by means of DB (2016). A Genetic Algorithm (GA) based on the NSGA-II method (Giamalaki et al., 2016) has been used, by setting a maximum number of generations to 200; each generation includes at most 20 designs. The computational domain is the whole year and the time interval between two consecutive energy balances has been fixed equals to 6 per hour. Obviously, the heat transfer method is based on transient energy simulations, much more reliable compared to steady-state methodologies. In order to evaluate the optimized solutions for building envelope, two objective functions have been considered and thus the minimization of heating load and the minimization of cooling load. Since several solutions can represent sub-optimal tradeoffs, the decision-maker can select the best one according to his criteria (Maddaloni et al., 2015). In particular, the final outcome is the Pareto front (Nguyen et al., 2014) which is the set of the nondominated solutions. In the proposed approach, among Pareto points, three solutions are discussed for further analysis: Solution that minimizes the heating demand, the cooling demand and solution for which the energy overall demand is minimized.

In a second phase, for these configurations, some interventions for the active energy systems are applied. These cumulative configurations are compared by using the cost-optimal methodology as established by EU Delegated Regulation (EUC, 2012).

It is based on the calculation of global cost, therefore it considers, for each energy efficiency measure, the initial investment, the sum of the annual costs referred to each year of operation (by including energy costs) and the final residual value, all with reference to the starting year (2016) of the calculation period. By assuming the macroeconomic prospective (in order to take into 
account also the environmental benefits), the global cost is shown in the Equation 1:

$$
C_{g}(\tau)=C_{I}+\sum_{j}\left[\sum_{i=1}^{\tau}\left(C_{a, i}(j) \cdot R_{d}(i)+C_{c, i}(j)\right)-V_{f, \tau}(j)\right]
$$

\section{Where:}

$\tau$ : $\quad$ Calculation period equal to 20 years

$C_{g}(\tau)$ : Global cost (referred to starting year) over the calculation period

$C_{I}$ : Initial investment costs for measure or set of measures $j$

$C_{a, i}(j)$ : Annual cost during the year i for measure or set of measures $j$

$C_{c, i}(j)$ : Annual cost of greenhouse gas emissions;

$V_{f, \tau}(j)$ : Residual value of measure or set of measures $j$ at the end of the calculation period (discounted to the starting year)

$R_{d}(i)$ : Yearly discount factor, assumed 3\%

The discount rate multiplies the periodic costs (as replacement costs and energy) and it is calculated according Equation 2, in which $R_{r}$ is the real interest rate:

$$
R_{d}(i)=\left(\frac{1}{1+R_{r}}\right)^{p}
$$

For the annual costs, the discount factor becomes, more properly, a present value factor $\left(f_{p v}\right)$, calculated as in Equation (3), where " $n$ " is the number of years considered for these costs:

$R_{d}(i) \rightarrow f_{p v}=\frac{1-\left(1+R_{r}\right)^{-n}}{R_{r}}$

Since the macroeconomic perspective has been adopted, the costs have been considered excluding the VAT. The monetary value of environmental damage for polluting emissions $\left(C_{c}\right)$, in terms of equivalent greenhouse gas emission, has been calculated by assuming an expected prices of $\mathrm{CO}_{2 \text {,eq }}$ equal to $20 € /$ ton until 2025, $35 € /$ ton until 2030 and $50 € /$ ton beyond 2030. These costs are those commonly considered in Europe. The emissions of equivalent carbon dioxide have been calculated by considering the emission factor for the combustion of natural gas and for electricity, respectively equal to $0.205 \mathrm{~kg} / \mathrm{kWh}$ and $0.563 \mathrm{~kg} / \mathrm{kWhel}$.

In this study, the annual costs are the sum of maintenance costs, operational costs, energy cost and replacement cost. The adopted economic parameters are shown in Table 1 according to the European indications (UNI, 2008). Moreover, natural gas and electricity tariffs, that include regional and national taxes, comply the billings.

\begin{tabular}{ll} 
Table 1. Economic parameters for global cost evaluation \\
\hline $\mathrm{R}_{\mathrm{r}}$ & $3.00 \%$ \\
\hline $\mathrm{R}_{\mathrm{d}}$ & $0.74(10$ years $)$ \\
& $0.64(15$ years $)$ \\
$\mathrm{f}_{\mathrm{pv}}$ & $0.55(20$ years $)$ \\
Natural gas cost & 14.9 \\
Electricity cost & $0.095\left[€ / \mathrm{kWh}_{\mathrm{gas}}\right]$ \\
\hline
\end{tabular}

In the following lines of the paper, the results are examined always by considering the primary energy saving $(\triangle \mathrm{EP})$ and the percentage reduction of the polluting emissions $\left(\Delta \mathrm{CO}_{2}\right)$.

Results of this investigation could be usefully considered by designers because these allow to know effect of selection for a large number and kind of energy retrofit actions and measures.

\section{Hospital Veneziale of Isernia}

\section{General Description}

Isernia is a city of Italian backcountry. It is within the Italian climatic zone "D", with medium-cold winters and warm summers, characterized by 1866 Heating DegreesDay (baseline $20^{\circ} \mathrm{C}$ ). The climate here is mild and generally temperate. The winter months are much rainier than the summer months and the mean annual rainfall is $811 \mathrm{~mm}$. With an average temperature of $22.1^{\circ} \mathrm{C}$, August is the hottest month of the year. January is the coldest month, with average daily temperatures of about $5.0^{\circ} \mathrm{C}$.

The 'Hospital Veneziale' (Fig. 1A) has been built between 1976 and 1986. The building that hosts the D.E.A. (hospitalization to high assistance and emergency) is more recent (1986-2002). The whole hospital complex has undergone several renovations, extension and maintenance works, particularly between 2002 and 2005, when the fire safety was improved. The building has a very articulated geometry, with the main face along the East-West axis; it could be seen as the aggregation of volumes with different shape and size, clearly distinguishable due to the different characteristics of the architectural solutions and external finishing. It has six usable floors above the ground and two underground stories. The gross volume is around $88^{\prime} 250 \mathrm{~m}^{3}$.

\section{Energy Audit and Simulation Model}

In order to simulate reliable energy performances, the Reference Building has been defined as the model with the energy performances deriving from the present building envelope and the present active systems' configuration. Thus, the numerical model has been characterized by data acquired by means of in-situ surveys, interviews with managers and occupants, infield measurements according to the tailored approach (EN15603, 2008). 


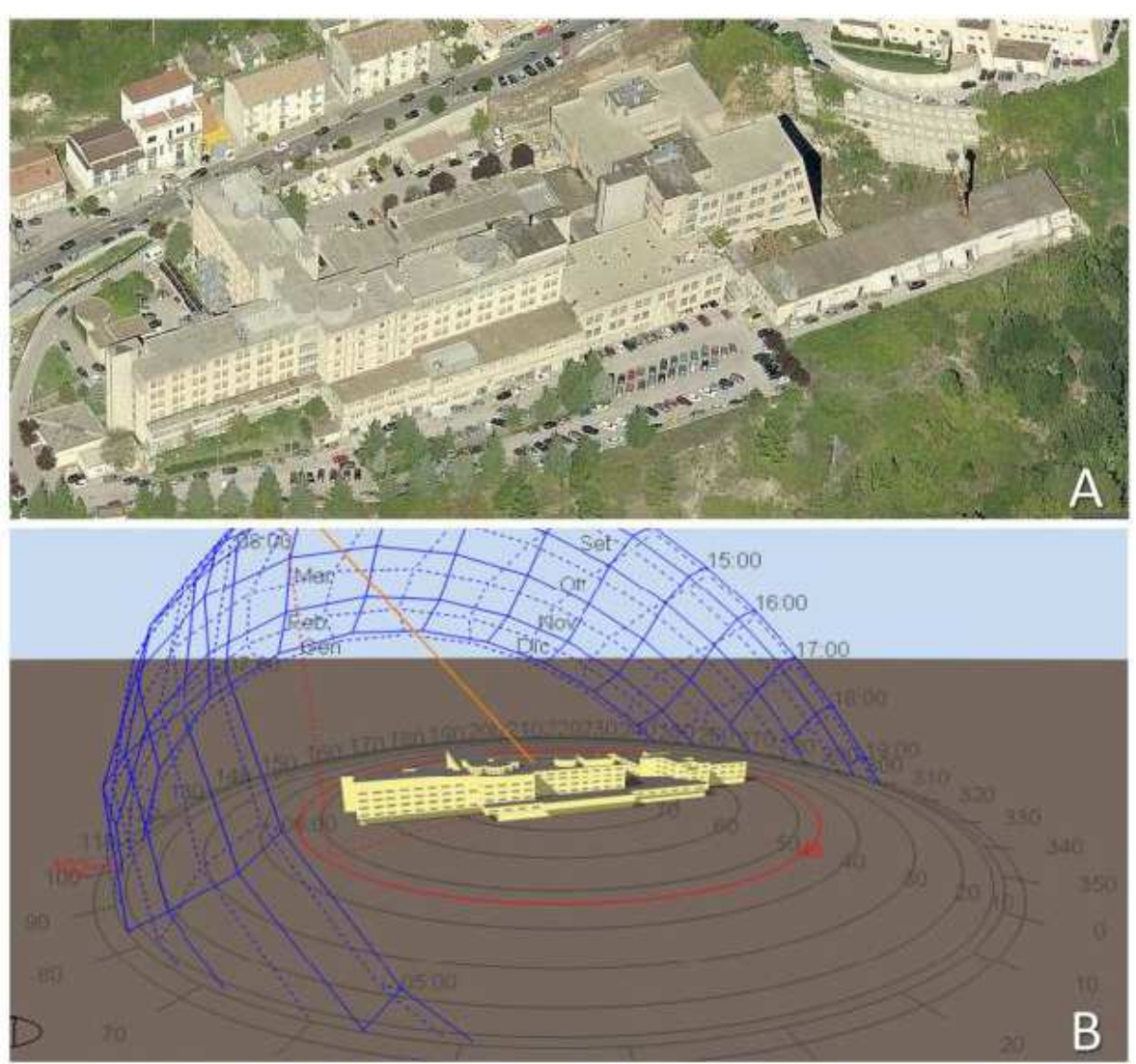

Fig. 1. (A) Building view; (B) Simulation model

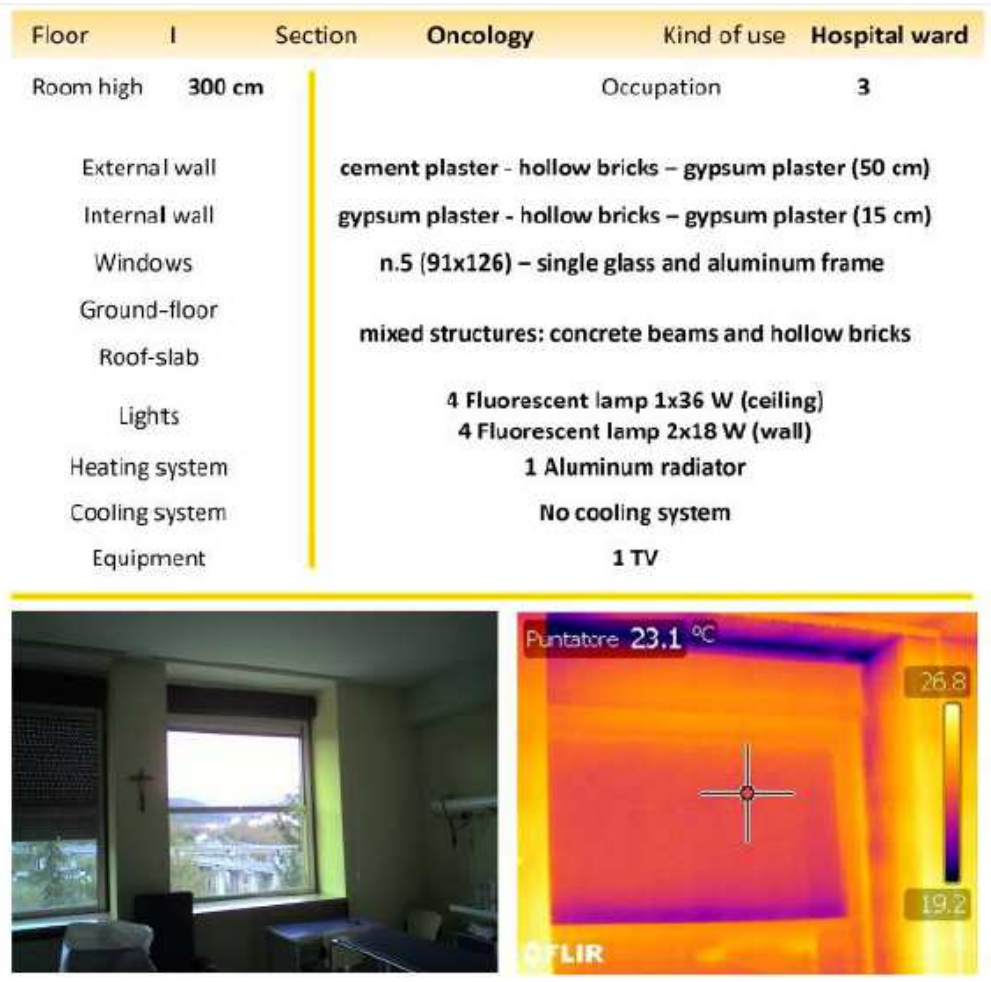

Fig. 2. Survey sheet for hospital ward of Oncology department 
For each room, the energy audit has been done using a survey matrix as shown in Fig. 2. In each room, also a thermo-graphic inspection has been performed, mainly for detecting heat losses, missing or damaged thermal insulation, thermal bridges and air leakages and for studying the fluid-dynamic of heating/cooling emitters.

The window-wall ratio is $18 \%$, with single glazed transparent components and metallic frame. The average estimated overall $U_{W}$ is $4.15 \mathrm{~W} /\left(\mathrm{m}^{2} \mathrm{~K}\right)$. The infrared inspection around the window's frame evidenced also air leakages and infiltrations. The air leakage increases both heating and cooling loads and it can cause thermal discomfort for the occupants. This aspect will be taken into account in the refurbishment process.

More in general, the energy audit allowed to evidence that the building has mixed concrete-brick structures.

Two types of walls are known: (a) Brick masonry with external plaster; (b). prefabricated vibrated concrete panels. Globally, the walls average thickness is $0.50 \mathrm{~m}$ and an average reliable thermal transmittance (U) is 1.58 $\mathrm{W} /\left(\mathrm{m}^{2} \mathrm{~K}\right)$. Ceiling, basement and roofs have mixed structures, given by the parallel presence of concrete beams, joists and interposed hollow bricks, without insulating layers (basement floor) or with a light insulation (roof). The thermal transmittance is around $1.80 \mathrm{~W} /\left(\mathrm{m}^{2} \mathrm{~K}\right)$ for the ground-floor and around 0.70 $\mathrm{W} /\left(\mathrm{m}^{2} \mathrm{~K}\right)$ for the roof slab. The air-conditioning system is greatly diversified. Generally, hospital wards have only heating systems with radiators, all surgery blocks and with rooms have all-air system, while usually, corridors, ambulatories and offices have a mixed air/water HVAC system, given by the combination of radiators and air handling units.

With reference to the heating systems, the hospital structure is equipped with two centralized generators of hot water, used for the space heating and DHW. The total thermal capacity is $7000 \mathrm{~kW}$ with a nominal efficiency of $96 \%$. Boilers and main circulation pumps are placed at the buried floors, while the main heat exchangers are decentralized at each block. For the space heating, heat exchangers provide thermal fluid at $80^{\circ} \mathrm{C}$, usable for the in-room terminals (radiators) and for the heating coils of the air-handling units. For the DWH production, there are 4 boiler of 5'000 1.

There are 11 air handling units (not equipped with heat recovery systems) that include liquid water humidifiers. For the cooling period, autonomous split systems are installed only in few rooms. Conversely, for the cooling period, the building is equipped with two water-cooled chillers, each one with a cooling capacity of 1'860 kW.

A fluorescent lighting system is installed in the whole building and, for each, room numbers and power of lamps have been surveyed. The numerical model of the 'Veneziale Hospital' has been simulated by means of
DesignBuilder (DB, 2016), the well-known graphical interface of EnergyPlus v 8.1 (U.S. 2016). Geometry and thermo-physics of the building and heating and cooling systems have been modeled according to the surveyed characteristics. Several thermal zones have been created, with collected data also in terms of occupation and operational schedules. This operation requires attention, as evidenced by Christiansen et al. (2016). In our study, the main ones are thus:

- Basement floor: Operating rooms, guardroom, preparing doctors, waiting rooms, corridors, archives, pharmaceutical laboratories, canteen and kitchen, stairs and services

- Ground floor: Emergency sector, corridors, toilet facilities, Changing rooms, medical offices, radiology, tomography, hemodialysis, psychiatry

- First floor: Cardiology, corridors, oncology, chemotherapy, hospital room, medical room

- Second floor: Corridors, surgeon, operating block, hypertensive center, corridors, toilet facilities

- Third floor: Clinics, corridors, nurse, operating rooms, guardroom, preparing doctors, waiting rooms

- Fourth floor: Corridors, medical clinics, medical offices, warehouses, anatomy, otorhinolaryngology;

- $\quad$ Fifth floor: Church

The heating period has been set as the Italian conventional for that climatic zone and thus from 15 October to 15 April with continuous operating schedule $(24 \mathrm{~h})$, while the cooling period has been assumed between 1 May to 30 September ( $10 \mathrm{~h}$ every day). The heating and cooling set point temperatures have been fixed to 20 and $26^{\circ} \mathrm{C}$, respectively, as usual in Italy. Then, the simulation outputs have been compared to the measured energy data, by determining the deviation and the relevant uncertainty of the numerical model according to the "Whole Building Level Calibration with Monthly Data" approach, described by the M\&V Guideline (U.S. 2008). The study is based on an analysis of the historical energy requests, by collecting data about the last available nine years (2005-2013), properly averaged.

Figure 3 shows the monthly demand provided by energy billings and simulation model, as well as the calculated EERmonth. As it can be seen, the simulated and real energy trends are quite similar. Moreover, the error in the annual energy consumption (EERaverage, year), is $+0.1 \%$, the mean bias error (MBE) is $-0.8 \%$ and the coefficient of variation of the root mean squared error CV(RMSEmonth) is 3.44\%. Typically, models are declared to be calibrated if these produce ERRmonth within $\pm 15 \%$, ERRaverage-year within $\pm 10 \%$, CV(RMSEmonth) within $\pm 10 \%$. All told, the energy model can be considered as well calibrated. 


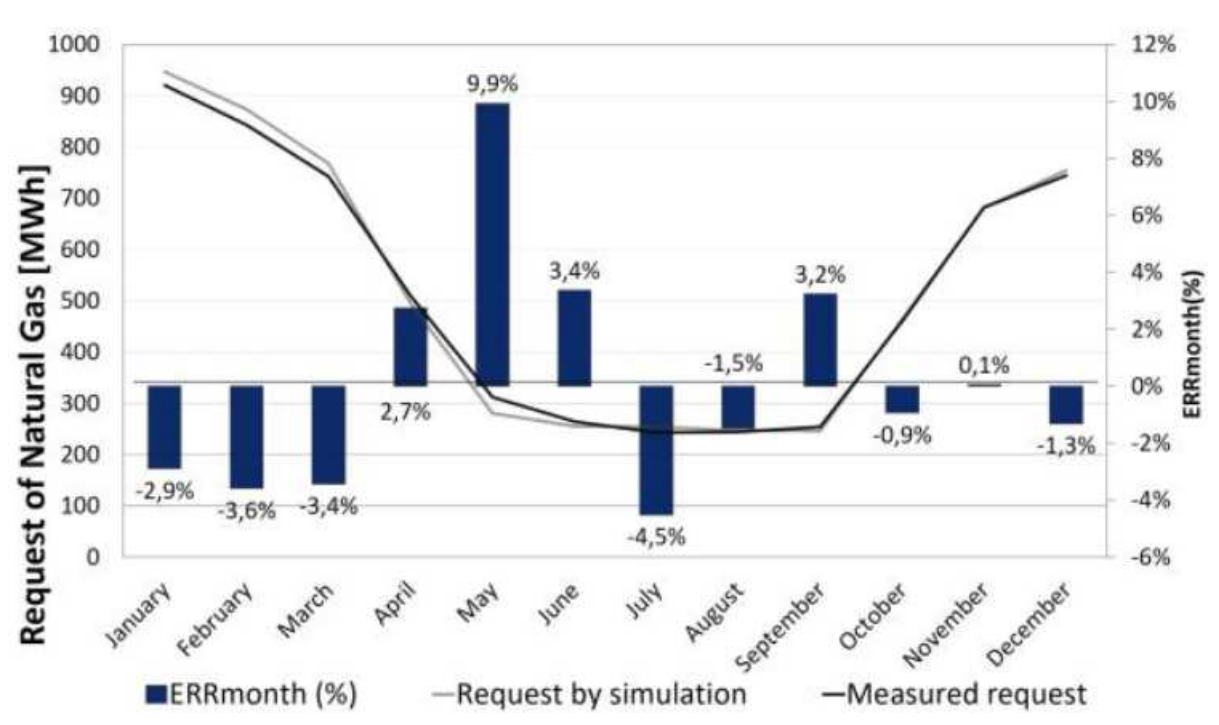

Fig. 3. Comparison between monthly real consumptions and results of the dynamic energy simulation

Table 2. Thermo-physical parameters for walls and roof

\begin{tabular}{lllll}
\hline & $U\left[\mathrm{~W} / \mathrm{m}^{2} \mathrm{~K}\right]$ & $M_{s}\left[\mathrm{~kg} / \mathrm{m}^{2}\right]$ & $\chi\left[\mathrm{kJ} / \mathrm{m}^{2} \mathrm{~K}\right]$ & $Y_{I E}\left[\mathrm{~W} / \mathrm{m}^{2} \mathrm{~K}\right]$ \\
\hline WE_10 & 0.307 & 1112 & 66.1 & 0.006 \\
WE_15 & 0.222 & 1113 & 66.1 & 0.004 \\
WE_20 & 0.174 & 1114 & 66.1 & 0.003 \\
WR_10 & 0.264 & 1121 & 66.1 & 0.005 \\
WR_15 & 0.189 & 1126 & 66.1 & 0.003 \\
WR_20 & 0.147 & 1131 & 66.1 & 0.002 \\
RE_10 & 0.331 & 497 & 75.5 & 0.062 \\
RE_15 & 0.234 & 497 & 75.4 & 0.014 \\
RE_20 & 0.181 & 498 & 75.3 & 0.010 \\
RR_10 & 0.281 & 505 & 75.4 & 0.017 \\
RR_15 & 0.197 & 510 & 75.3 & 0.011 \\
RR_20 & 0.152 & 515 & 75.3 & 0.007 \\
\hline
\end{tabular}

The same evaluations have been done for electricity, also in this case with a very good accordance. Briefly, the whole simulated consumption is $3.53 \mathrm{GWh}$ and the ERRaverage year is $7.0 \%$.

\section{Selection of Suitable Energy Efficiency Measures}

The energy audit has given suggestions about the following possible energy efficiency measures:

- Increment of thermal insulation of present building is studied, by considering the application of 10,15 or $20 \mathrm{~cm}$ of insulation for both walls and roof slab. The Table 2 show stationary and dynamic parameters of each configuration. Here, WE and WR indicate respectively wall with expanded polystyrene as insulation $(\lambda \approx 0.040 \mathrm{~W} / \mathrm{mK})$ or Rockwool $(\lambda \approx 0.033 \mathrm{~W} / \mathrm{mK})$ and the number indicates the thickness of insulation; at the same manner, RE and RR indicate roof insulation. Moreover, $M_{s}$ is the thermal mass, $\chi$ indicates the internal areal heat capacity and $\mathrm{Y}_{\mathrm{IE}}$ is the periodic thermal transmittance
- Adoption of a cool paint (solar reflectance $\mathrm{SR} \approx$ 0.8 , infrared emissivity $\varepsilon \approx 0.9$ ) for roof slab and/or low-emissive aluminum coating ( $\mathrm{SR} \approx$ $0.56, \varepsilon \approx 0.48$ ) is investigated

- Replacement of the windows with more efficient technological solutions is evaluated; Table 3, where $U_{g}$ is the thermal transmittance of glazed system and $g$ is the solar factor (solar transmittance)

- Different kinds of window frame, as well as various external and internal shading systems, are considered as indicated in Table 3

As said, some interventions have been considered also for the active energy systems and thus:

- Installation of LED lamps, with nominal power of $20 \mathrm{~W}$, high luminous efficiency and color rendering index greater than 80

- HVAC intervention: (a) Adoption of sensible heat recovery for each air-handling unit. More in 
deep, a Flat Plate Heat Exchanger is used with sensible efficiency - at $100 \%$ air flow - of 0.70 . No latent recovery is chosen, because of the risk of contamination; (b) attenuation of set-point temperature during the nighttime of heating season: $18^{\circ} \mathrm{C}$ from $00: 00$ until $6: 00 ; 20^{\circ} \mathrm{C}$ for the other hours

Finally, the need of supply clean and renewable energy for supporting the energy demand of the building is considered and thus the installation of PV is analyzed.

\section{Refurbishment Design Optimization: Results and Discussion}

For evaluating the described energy efficiency measures, the reference configuration is the present building. The simulation model suggests that, by assuming an average efficiency of the Italian power systems equals to $42 \%$ (EEA, 2017), the overall primary energy demand (EP) is $14.6 \mathrm{GWh}$. This energy request corresponds to operating costs of 1'413'000 €/y and to polluting emissions of 3'252 $\mathrm{tCO}_{2}$.

The energy demand for space heating (gas + auxiliaries) accounts for $48 \%$ of the whole demand. Electricity request for summer cooling is around $17 \%$ of total electricity demand.

Moreover, the reference configuration is characterized by heating thermal need of 2'816 MWh and cooling thermal need of 1'414 MWh.

Table 3. Variable for glazing components

\begin{tabular}{ll}
\hline Variable & Description \\
\hline Glazing type
\end{tabular}

- Dbl Clr 6/13/6 Argon: $\mathrm{U}_{\mathrm{g}} \approx 2.55 \mathrm{~W} /\left(\mathrm{m}^{2} \mathrm{~K}\right), \mathrm{g}=0.70$

- Dbl LoE 3/13/3 Argon: $\mathrm{U}_{\mathrm{g}} \approx 2.04 \mathrm{~W} /\left(\mathrm{m}^{2} \mathrm{~K}\right), \mathrm{g}=0.69$

- Trp Clr 3/13/3 Argon: $\mathrm{U}_{\mathrm{g}} \approx 1.62 \mathrm{~W} /\left(\mathrm{m}^{2} \mathrm{~K}\right), \mathrm{g}=0.68$

- Trp LoE 3/13/3 Argon: $\mathrm{U}_{\mathrm{g}} \approx 0.78 \mathrm{~W} /\left(\mathrm{m}^{2} \mathrm{~K}\right), \mathrm{g}=0.47$

- Trp LoE Sel 6/13/6/13/6 Air: $\mathrm{U}_{\mathrm{g}} \approx 1.22 \mathrm{~W} /\left(\mathrm{m}^{2} \mathrm{~K}\right), \mathrm{g}=0.36$

Window frame

- UPVC window frame

- Wooden window frame

- Aluminium window frame (with thermal break)

Local shading type

- No shading

- Projection Louvre from 0.5 to $1.5 \mathrm{~m}$

- Overhang from 0.5 to $2.0 \mathrm{~m}$

Window blind type

- None

- Blind with medium reflectivity slats

- Blind with low reflectivity slats

- Shade roll- medium opaque

\section{Optimization of Envelope Refurbishment Design}

Around 260 simulations of combined measures (Fig. 4) have been automatically performed. The red point has been added to evidence the base case position. In Fig. 4, the position of solutions that consider only interventions on Opaque Envelope (Op_ENV) or on Glazed Components (Gl ENV) have been evidenced. Note that adoption of cool roof is never considered in the optimal solutions. Indeed, of course, it causes an increase of heating load. It should be noted that, in the optimization, a constraint concerning a maximum number of discomfort hours has been considered.

The solution of optimization problem generates a Pareto front with yellow points. A global overview allows to remark that the replacement of old windows is always an optimal solution. Pareto front considers double (3 points) or triple low-emissive ( 9 points) and selective glazing system. The most frequent local shading type is the projection louvre $(1.0 \mathrm{~m})$ and only few points $(8)$ take into account also internal shading. There are not substantial differences by changing the windows' frames.

As regard the opaque envelope for wall, the application of $20 \mathrm{~cm}$ of rock-wool seems to be the best solution and it is verified also for the roof slab. In this case, one Pareto point requires only $15 \mathrm{~cm}$ of insulation (EPS) and another configuration proposes low-emissive paint and $10 \mathrm{~cm}$ of insulation.

Finally, three points have been selected on the Pareto front:

- OpW: ( $\mathrm{W}=$ winter) the configuration that minimizes the heating load

- OpS: ( $\mathrm{S}=$ summer) the configuration that minimizes the cooling load

- OpTOT: the configuration that minimizes the sum of heating and cooling loads

The OpW requires the installation of triple low emissive windows with UPVC frame and projection louvre $(1.0 \mathrm{~m})$ as external shading and no inner shading system. For wall and roof slab, the application of $20 \mathrm{~cm}$ of rock-wool is the most suitable solution. This configuration allows energy saving during the heating season of around $18 \%$ and the EP is equal to 13 ' 120 $\mathrm{MWh}(-10 \%$ of $\mathrm{RB})$; this corresponds to operating costs of 1 ' 273 ' $127 € / y$ and a reduction of polluting emissions of around $9 \%$.

The OpS point is characterized by the same solutions for the opaque envelope of $\mathrm{OpW}$, while for windows the adoption of triple selective glass and UPVC frame is suggested. The external shading should be the overhanging system $(1.0 \mathrm{~m})$ and the shade roll should be installed on the inner side. In this case, the total primary demand is around 13'055 MWh; the reduction of operating costs and of polluting emissions is around $11 \%$. 
The minimization of total load (OpTOT) requires always the insulation of walls and roof with $20 \mathrm{~cm}$ of rock-wool; conversely, for the glazed components, the installation of triple selective windows, with UPVC frame without external shading system but only shade rolls, is considered. In this case, the reduction of total primary energy demand is around $12 \%$ and operating costs and polluting emissions are reduced of around $11 \%$.

\section{Cost-Optimal Analysis}

The three selected configurations (i.e., OpW, OpS and OpTOT) are here combined with the two proposed interventions for lighting and HVAC systems. Table 4 summarizes the investment cost and the lifespan (p) (UNI, 2008).

Merely for the heat recovery, a maintenance cost has to be taken into account, by considering a rate of $2 \% /$ year of the investment cost. Finally, Fig. 5 compares the selected efficiency measures in terms of primary energy request and global cost $\left(\mathrm{C}_{\mathrm{g}}\right)$. Note that for this analysis, EP includes energy demand for all uses of the hospital, not only those for the air-conditioning and microclimatic control.

The plotted curve is a possible set of optimal solutions characterized by lowest costs, assuming as first point the building with its actual performance. For this basic scenario, $C_{g}$ is around $850 € / \mathrm{m}^{2}$, by considering a total surface area of the building of $27^{\prime} 345 \mathrm{~m}^{2}$ (this is the sum of all surfaces of used stories).

Figure 5 shows that the integration of energy efficiency measures on the building envelope with the replacement of lighting system allows to reduce the EP between $16 \%(\mathrm{OpW}+\mathrm{LED})$ and $20 \%(\mathrm{OpS}+\mathrm{LED})$ and $C_{g}$ is reduced of around $13 \%$ in the best case. Otherwise, the combination of envelope measures and HVAC interventions assures, in the best case (OpS + REC), energy saving of around $16 \%$ and reduction of global cost of around $9 \%$. We can conclude that the optimal solution is OpS + LED + REC and thus: Insulation of roof and walls with $20 \mathrm{~cm}$ of rock-wool; adoption of triple selective glass with UPVC frame and external overhang combined with internal shade rolls; replacement of existing lamp with LED; installation of heat recovery systems and attenuation of nighttime heating without compromising the thermal comfort. With this configuration, the overall energy demand is reduced of $21 \%$ and the global cost has saving of about $15 \%$. More in detail, the heating demand (gas and auxiliaries) is reduced of $29 \%$ and the cooling demand of $7 \%$; the reduction of polluting emissions account for around $22 \%$. This underlines that, also in heating dominated climates, the high endogenous heat gains of hospitals require a deep attention toward energy efficiency measures aimed at reducing also the cooling need. Similar outcomes were achieved by Ascione et al. (2016).

Finally, a sensitivity analysis (Fig. 6) has been carried out for different discount rates. More in detail, the global cost has been calculated by using real interest rate of $1.5 \%$ (very low inflation rate) and $6.0 \%$.

Table 4. Cost, lifespan of building elements and plant system

\begin{tabular}{lll}
\hline & $\mathrm{C}_{\mathrm{I}}$ & $\mathrm{p}$ [years] \\
\hline Window: Trp LoE + UPVC & $300 € / \mathrm{m}^{2}$ & 35 \\
Window: Trp LoE Sel + UPVC & $320 € / \mathrm{m}^{2}$ & 35 \\
External shading system & $80 € / \mathrm{m}^{2}$ & 50 \\
Internal shading & $40 € / \mathrm{m}^{2}$ & 20 \\
Insulation: WR_20 & $96 € / \mathrm{m}^{2}$ & 50 \\
Insulation: RR_20 & $69 € / \mathrm{m}^{2}$ & 50 \\
Heat recovery & $4500[1$ unit] & 20 \\
LED & $20[1$ unit] & 20 \\
\hline
\end{tabular}

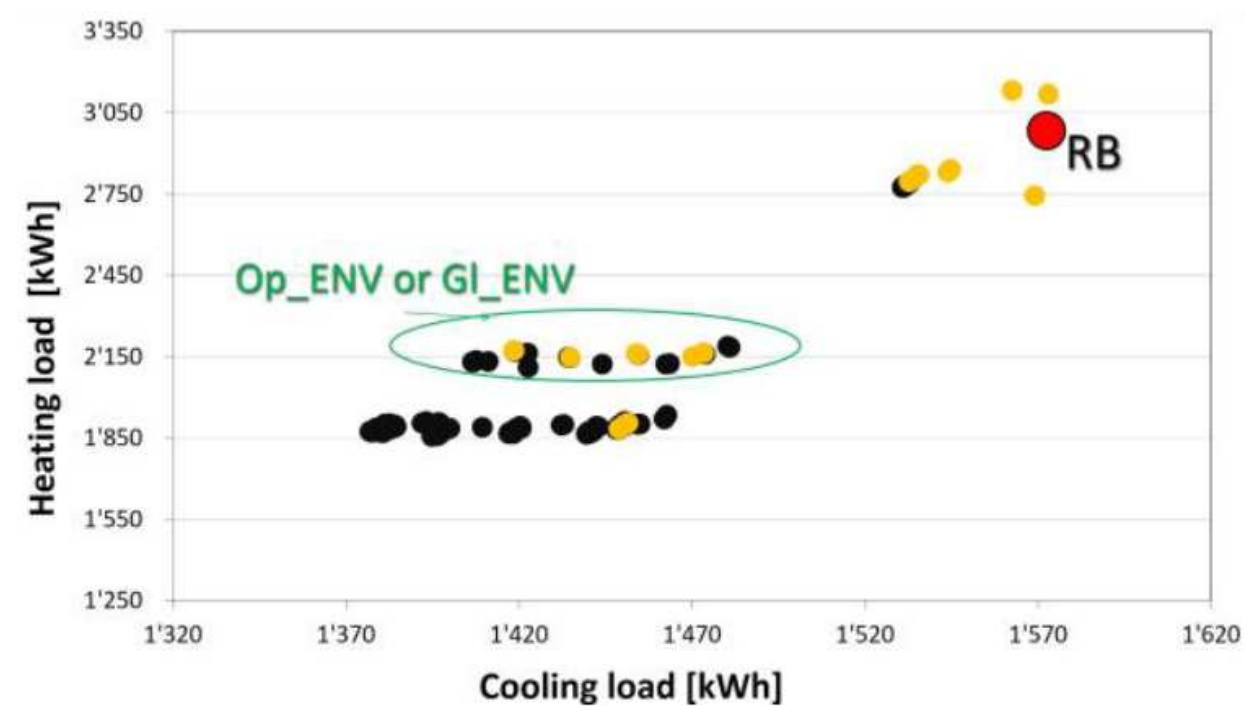

Fig. 4. Optimization results for opaque and glazed envelope 


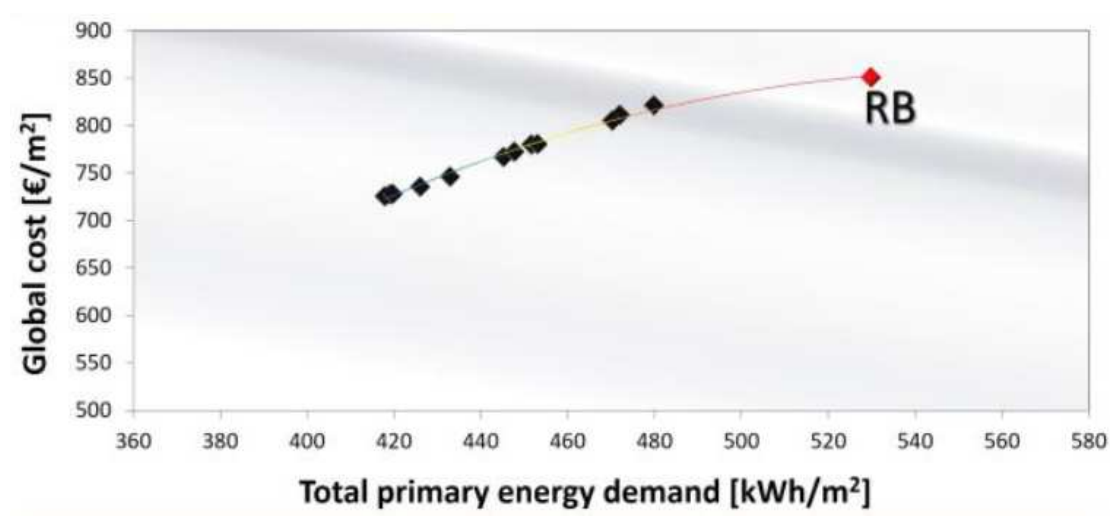

Fig. 5. Cost optimal level for selected energy efficiency measures
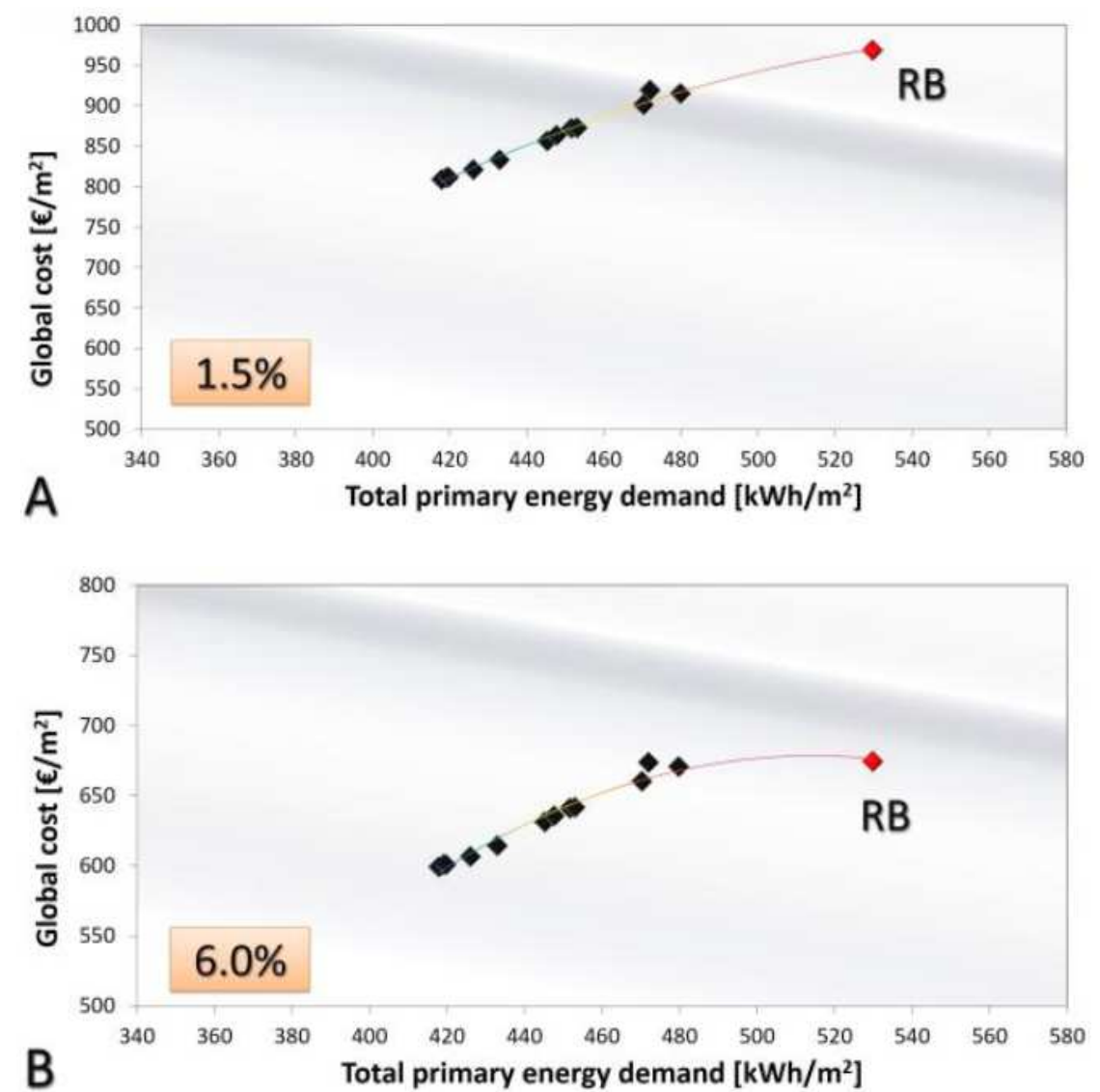

Fig. 6. Cost optimal level: (a) interest rate of 1.5\%; (b) interest rate of $6.0 \%$

A lower interest rate results in increased discount rate ( $R_{d}$ is equal to 0.86 for lifespan of 10 years and 0.74 for 20 years) as well as in an increased incidence of annual costs because the present value factor is higher (17.2).

The reference case has global cost of around 969 $€ / \mathrm{m}^{2}$ (Fig. 6a) and three configurations allow the same reduction $(-16 \%)$ of $\mathrm{C}_{\mathrm{g}}$; these are:

- $\quad \mathrm{OpW}+\mathrm{REC}+\mathrm{LED}$
- $\mathrm{OpS}+\mathrm{REC}+\mathrm{LED}$

- OpTOT + REC + LED

Conversely, for interest rate of $6.0 \%$ (Fig. 6b), the present value factor is 11.5 and also the discount rate is lower $\left(R_{d} \approx 0.56\right.$ for lifespan of 10 years and 0.33 for 20 years). In this scenario, the annual costs incidence is reduced and the overall cost for RB became $674 € / \mathrm{m}^{2}$. 

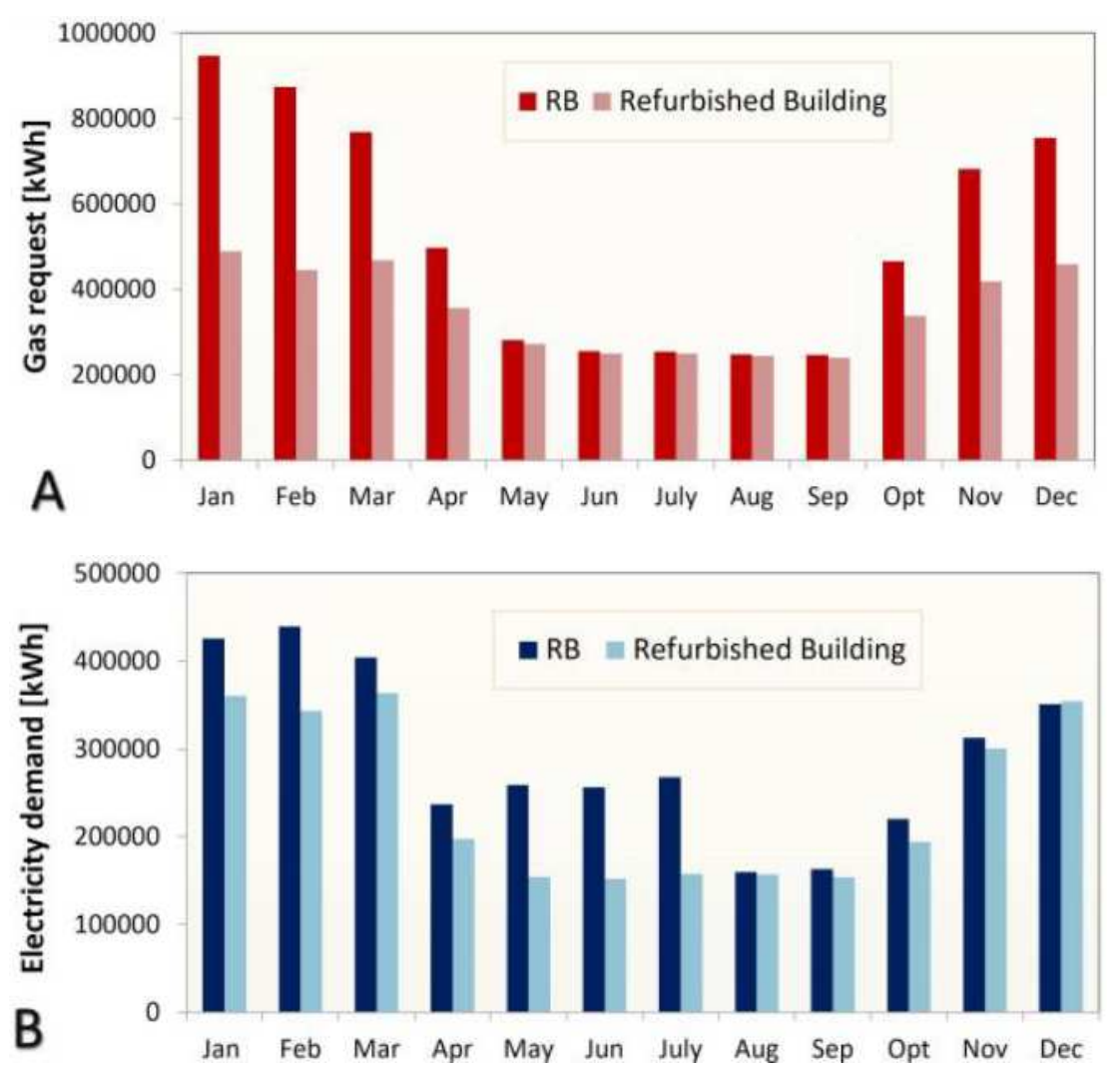

Fig. 7. Final outcomes for comparing base case and refurbished buildings: (a) gas demand; (b) electricity

In this case the only application of efficiency measures for the building envelope does not determine a sensible reduction of $C_{g}(\approx-1.0 \%)$. The best solution is always OpS + LED + REC, with a reduction of global cost of around $-11 \%$. Also the sensitivity analysis confirm the optimal solution found in Fig. 5.

In a further deepening, the achieved optimal configuration has been coupled with the installation of PV panels, facing southeast and placed on the building roof. The installed nominal power is 100 $\mathrm{kWp}$ (by considering only the roof surface of the last floor) and the cost of PV technology has been assumed of 1'600 $€ / \mathrm{kWp}$. The European PV calculation sheet (PV-GIS, 2017) has been used to simulate the electric conversion capability. The evaluation takes into account the rated power, the angle of inclination according to a complete integration with the roof, the losses of the PV generator.

More in detail, the energy losses (resistive and due to the difference in temperature of modules, reflection and mismatching between strings), the efficiency of the inverter, as well as the reflection coefficient of the ground in front of the modules (albedo) have been considered. The main input data are listed in Table 5 (these are referred to the chosen commercial polycrystalline panel).
Table 5. Characteristics of the PV module

\begin{tabular}{ll}
\hline Module dimensions & $1655 \times 989 \times 39 \mathrm{~mm}$ \\
\hline Rated power & $250 \mathrm{~W}$ \\
Efficiency & 15.3 \\
Losses-low temperature/irradiance & $9.6 \%$ \\
Loss-angular reflectance effects & $2.7 \%$ \\
Other losses & $14.0 \%$ \\
\hline
\end{tabular}

After the photovoltaic installation, the energy balance of the building was analyzed in terms of electricity, on an annual basis. Finally, the energy conversion from renewable sources (136'110 kWh annually) balances around $4.5 \%$ of annual electricity request.

By considering the contemporaneity of production and demand (because of the diurnal use of the building and the small size of PV installation), it can be considered that all electric energy from photovoltaics is used by the building itself.

All told, by taking into account this final scenario, Fig. $7 \mathrm{a}$ and $7 \mathrm{~b}$ show the comparison between gas and electricity demands, respectively, for the reference building and the refurbished one. The refurbished building allows to reduce the gas demand of around 32\% and the electricity consumption has savings of about $17 \%$. The polluting emissions are reduced of $24 \%$. Finally, it has to be remarked that all proposed interventions, according to a Simple Payback 
calculation, are repaid in around 7 years. Of course, it is a good result, but however this period can be shortened if incentives are considered.

\section{Conclusion}

The paper has presented the application of a multistage optimization methodology for the selection of suitable energy conservation measures, in order to improve the energy performances of hospital building in a typical heating dominated climate. The proposed approach, carefully detailed for the case study of the 'Ospedale Veneziale' of Isernia (Italy), is aimed to suggest a procedural method to design the refurbishment of high-complex building types. It consists of an accurate energy audit in order to characterize the envelope/HVAC systems, as well as the thermal zones; these data are used to define and calibrate the energy simulation model of the building. In detail, the proposed approach for studying the applicable energy efficiency measures consists of optimization process with two sequential phases. First of all, a multi-objective optimization with genetic algorithm is performed in order to provide the best trade-off between transparent envelope solutions, insulation of the building and radiative characteristics of roof. Among Pareto points, three solutions are considered: Solution that minimizes the heating demand, or the cooling demand or solution that assures a minimized overall energy demand.

In a second phase, for these configurations, some interventions for the active energy systems are applied. These cumulative configurations are compared by using the cost-optimal methodology with macroeconomic approach.

For the case study, the optimal solution $\left(\Delta C_{g} \approx-15 \%\right)$ requires: (a) The insulation of roof and walls with 20 $\mathrm{cm}$ of rock-wool; (b) the adoption of a triple selective glass with UPVC frame and external overhanging shadings combined with internal shade rolls; (c) the replacement of existing lamp with LED and (d) the installation of heat recovery and (e) attenuation of nighttime heating without compromising the thermal comfort. Moreover, the installation of a PV-system of $100 \mathrm{kWp}$ is recommended. These refurbishment solutions allow to reduce the gas demand of around $32 \%$, the electricity consumption of around $-17 \%$ and the polluting emissions of $-24 \%$. According to a Simple Payback calculation, these efficiency measures can be repaid in around 7 years.

Finally, it should be remarked that some general indications can be obtained from the results of case study. In heating dominated climates, insulation material with low conductivity and high mass should be considered both for walls and roof. Adoption of high reflective materials are never suitable. Windows should be triple selective systems and both external and internal shading systems (more in detail, overhanging devices and shade roll) are suitable. The interventions on HVAC and lighting systems allow considerable energy savings with reduced time back periods. Moreover, peculiarities of hospitals, such as high internal loads, require also a perspective of energy retrofit looking to the reduction of thermal discomfort due to indoor overheating. Finally, measures for reducing the cooling loads are suitable in all climates.

\section{Acknowledgement}

The authors would like to thank administration and staff of the Ospedale Veneziale of Isernia, Italy. Moreover, we thank the editor and the anonymous reviewers for the careful evaluation and all given advices.

\section{Author's Contributions}

Fabrizio Ascione and Rosa Francesca De Masi: Have provided the literature investigations and the development of the numerical studies.

Gennaro Sosto and Giuseppe Peter Vanoli: Have contributed in coordination, data analysis and writing of the manuscript. All authors have contributed with the same weight (i.e., equal contributions).

\section{Ethics}

The authors declare that there are not ethical issues that could arise after the publication of this study.

\section{References}

AIA, 2006. Guidelines for Design and Construction of Hospital and Healthcare Facilities. 1st Edn., American Institute of Architects Press, Washington.

Ascione, F., N. Bianco, C. De Stasio, G.M. Mauro and G.P. Vanoli, 2016a. Multi-stage and multi-objective optimization for energy retrofitting a developed hospital reference building: A new approach to assess cost-optimality. Applied Energy, 174: 37-68. DOI: $10.1016 /$ j.apenergy.2016.04.078

Ascione, F., 2017. Energy conservation and renewable technologies for buildings to face the impact of the climate change and minimize the use of cooling. Solar Energy.

DOI: $10.1016 /$ j.solener.2017.01.022

ASHRAE, 2011. Chapter 8 Health care facilities, in HVAC Applications Handbook. American Society of Heating, Refrigeration and Air-Conditioning Engineers Inc., Atlanta, GA. 
Biglia, A., Caredda, F.V., Fabrizio, E., Filippi, M., Mandas, N., 2017. Technical-economic feasibility of CHP systems in large hospitals through the Energy Hub method: The case of Cagliari AOB. Energy and Buildings, 147: 101-112. DOI 10.1016/j.enbuild.2017.04.047.

Buonomano, A., Calise. F., Ferruzzi, G., Palombo, A., 2014. Dynamic energy performance analysis: Case study for energy efficiency retrofits of hospital buildings. Energy 78: 555-572.

DOI: $10.1016 /$ j.energy.2014.10.042

Capozzoli, A., M.S. Piscitelli, F. Neri, D. Grassia and G. Serale, 2016. A novel methodology for energy performance benchmarking of buildings by means of Linear Mixed Effect Model: The case of space and DHW heating of out-patient Healthcare Centres. Applied Energy, 171: 592-607.

DOI: 10.1016/j.apenergy.2016.03.083

Carbonari, A., R. Fioretti, M. Lemma and P. Principi, 2015. Managing energy retrofit of acute hospitals and community clinics through EPC contracting: The MARTE project. Energy Proc., 78: 1033-1038. DOI: 10.1016/j.egypro.2015.11.054

Christiansen, N., Kaltschmitt, M., Dzukowski, F., 2016. Electrical energy consumption and utilization time analysis of hospital departments and large scale medical equipment. Energy Buildings, 131: 172-183. DOI 10.1016/j.enbuild.2016.09.023

DB, 2016. Design Builder v.4.7.

EN15603, 2008. European committee for standardization, standard, energy performance of buildings-overall energy use and definition of energy ratings.

EEA, 2017. Efficiency of conventional thermal electricity and heat production. European Environmental Agency.

EPTA Ltd., 2007. Guidelines for energy efficiency in hospitals. EPTA Ltd.

EUP, 2010. Directive 2010/31/EU of the European parliament and of the council of 19 May 2010 on the energy performance of buildings (recast). Official Journal of the European Union.

EUC, 2012. Delegated regulation $N^{\circ}$ 244/2012 of 16 January 2012 supplementing directive 2010/31/EU of the European parliament and of the council on the energy performance of buildings by establishing a comparative methodology framework for calculating costoptimal levels of minimum energy performance requirements for buildings and building elements. Official Journal of the European Union.
Giamalaki, K., F. Mohammad and M. Thysell, 2016. Global climate classifications according to the Köppen climate classification. Lundus University.

IMPW, 1974. Italian ministry for public works. Circular n. 13011.

ISPESL, 2002. Guidelines for the definition of safety standards and environmental health for departments of operators. Italian National Institute for Prevention and Work Safety.

Maddaloni, A., G.F. Porzio, G. Nastasi, V. Colla and T.A. Branca, 2015. Multi-objective optimization applied to retrofit analysis: A case study for the iron and steel industry. Applied Thermal Eng., 91: 638646. DOI: 10.1016/j.applthermaleng. 2015.08.051

Nguyen, A.T., S. Reiter and P. Rigo, 2014. A review on simulation-based optimization methods applied to building performance analysis. Applied Energy, 113: 1043-1058.

DOI: 10.1016/j.apenergy.2013.08.061

PIR, 1997. President of Italian republic. Presidential Decree.

PV-GIS Software, 2017. European commission. Joint Research Centre, Institute for Environment and Sustainability, Renewable Energies Unit.

Radwan, A.F., A.A. Hanafy, M. Elhelw, A. El-Hamid and A. El-Sayed, 2016. Retrofitting of existing buildings to achieve better energy-efficiency in commercial building case study: Hospital in Egypt. Alexandria Eng. J., 55: 3061-3071. DOI: 10.1016/j.aej.2016.08.005

Sattayakorn, S., M. Ichinose and R. Sasaki, 2017. Clarifying thermal comfort of healthcare occupants in tropical region: A case of indoor environment in Thai hospitals. Energy Build., 149: 45-57. DOI: $10.1016 /$ j.enbuild.2017.05.025

Teke, A. and O. Timur, 2014. Assessing the energy efficiency improvement potentials of HVAC systems considering economic and environmental aspects at the hospitals. Renewable Sustainable Energy Rev., 33: 224-235.

DOI: 10.1016/j.rser.2014.02.002

Wang, T., X. Li, P.C. Liao and D. Fang, 2016. Building energy efficiency for public hospitals and healthcare facilities in China: Barriers and drivers. Energy, 103: 588-597. DOI: 10.1016/j.energy.2016.03.039

UNI, 2008. Italian Unification Body, UNI EN 15459:2008, Energy performance of buildings Economic evaluation procedure for energy systems in buildings, 3.7.2008.

U.S., 2016. Department of Energy, Energy Plus simulation software, Version 8.1.0.

U.S., 2008. Department of Energy Federal Energy Management Program, M\&V Guidelines: Measurement and Verification for Federal Energy Projects, Version 3.0, 2008, Boulder (United States). 


\section{Abbreviations and Acronyms}

$\mathrm{C}_{\mathrm{a}}$,

$\mathrm{C}_{\mathrm{c}}$,

$\mathrm{C}_{\mathrm{g}}$

$\mathrm{C}_{\mathrm{I}}$

$\mathrm{CO}_{2, \mathrm{eq}}$

$\varepsilon$

EP

$\mathrm{f}_{\mathrm{pv}}$

$\mathrm{g}$

$\lambda$

OpS

OpTOT

OpW

$\mathrm{R}_{\mathrm{d}}$

$\mathrm{R}_{\mathrm{r}}$

$\mathrm{S}$

SR

$\mathrm{S} / \mathrm{V}$

$\mathrm{U}$

$\mathrm{U}_{\mathrm{g}}$

$\mathrm{U}_{\mathrm{w}}$

$\mathrm{Y}_{\mathrm{IE}}$

MBE

$\mathrm{M}_{\mathrm{c}}$

$\mathrm{M}_{\mathrm{s}}$

$\mathrm{p}$

$\mathrm{t}$

$\mathrm{V}_{\mathrm{f}, \tau}$

$\chi$
Annual cost for retrofit measures

Annual cost of greenhouse gas emissions

Global cost

Investment cost

Equivalent emissions per year

Infrared emissivity

Primary energy request

Present value factor

Solar factor

Thermal conductivity

Optimal summertime solution

Global optimal solution

Optimal wintertime solution

Discount rate

Real interest rate

Thickness

Solar reflectance

Surface to volume ratio

Stationary thermal transmittance

Glass thermal transmittance

Window thermal transmittance

Periodic thermal transmittance

Mean bias error

Percentage for repair and service costs

Thermal mass of a building component

Lifespan of components

Calculation period

Residual value of retrofit measures

Internal areal heat capacity
$[€]$

$[€]$ or $[€ /$ ton $]$

$[€]$ or $\left[€ / \mathrm{m}^{2}\right]$

$[€]$ or $\left[€ / \mathrm{m}^{2}\right]$

$[\mathrm{t} / \mathrm{y}]$ or $[\mathrm{kg} / \mathrm{y}]$

[---]

[kWh $\mathrm{kRIMARY}_{\text {PRI }}$

[\%]

[\%]

$[\mathrm{W} / \mathrm{mK}]$

$---$

$---$

[\%]

[\%]

[m]

[\%]

$\left[\mathrm{m}^{-1}\right]$

$\left[\mathrm{W} / \mathrm{m}^{2} \mathrm{~K}\right]$

$\left[\mathrm{W} / \mathrm{m}^{2} \mathrm{~K}\right]$

$\left[\mathrm{W} / \mathrm{m}^{2} \mathrm{~K}\right]$

$\left[\mathrm{W} / \mathrm{m}^{2} \mathrm{~K}\right]$

[\%]

[\%]

$\left[\mathrm{kg} / \mathrm{m}^{2}\right]$

[y]

[y]

[y]

$\left[\mathrm{kJ} / \mathrm{m}^{2} \mathrm{~K}\right]$ 